\title{
Variation in Disease Incidence of Phomopsis Cane and Leaf Spot of Grape in Commercial Vineyards in Ohio
}

\author{
M. Nita, Kansas State University, Manhattan 66506; and M. A. Ellis and L. V. Madden, The Ohio State University, \\ Ohio Agricultural Research and Development Center, Wooster 44691
}

\begin{abstract}
Nita, M., Ellis, M. A., and Madden, L. V. 2008. Variation in disease incidence of Phomopsis cane and leaf spot of grape in commercial vineyards in Ohio. Plant Dis. 92:1053-1061.

A statewide survey for incidence of Phomopsis cane and leaf spot of grape (caused by Phomopsis viticola) was conducted during the 2002 to 2004 growing seasons. Over the 3 years, disease was observed in all surveyed vineyards, and mean disease incidence for leaves and internodes was 42 and 50\%, respectively. A hierarchical linear mixed model was used to evaluate effects of region, farm within region, vineyard within farm, sampling site (i.e., vine) within vineyard, and shoot (i.e., cane) within vine on disease incidence. Region of the state did not have a significant effect on incidence but there was significant variation at all other levels of the hierarchy $(P<$ 0.05 ); the greatest variation was at the lowest scale (shoots within vines). The potential effects of weather and management practices on disease risk at the vineyard scale were determined by using nonparametric correlation and binary logistic analyses after first classifying mean incidence per vineyard as being below or above 20\% (D20 = 0,1) and 40\% (D40 = 0,1). Overall results indicated that variables for predicted number of moderate infection events (DM; based on ambient temperature and hours when either there was measured rainfall or relative humidity above 90\%), the extent of fungicide application (C) during early- and mid-May (M1 and M2, respectively), and the use of a dormant-period application of fungicide (DOR) were the key factors in predicting disease risk (for either D20 or D40). Accuracy (percentage of high and low disease vineyards correctly predicted) and area under the receiver operating characteristic curve (an overall measure of the accuracy of a model) for a generic model combining these predictor variables were 74 and 0.84 , respectively, for D40 and 87 and 0.97, respectively, for D20. Models based on management practices were as accurate as those that incorporated weather variables. Although the degree of control of this disease is inadequate in Ohio, based on the survey results for incidence, the results from the risk-model analysis showed that improved management might be obtained by applying fungicide early during the growing season.
\end{abstract}

Additional keywords: Kendall correlation, sensitivity, specificity, ROC

Phomopsis cane and leaf spot is a disease of grape caused by the fungus Phomopsis viticola (Sacc.) Sacc. (26). Various parts of the vine, including leaf, cane, rachis, and fruit, can be infected by $P$. viticola. Symptomatic leaves show small, irregular or round, pale green-to-yellow spots with dark centers. Brown-to-black necrotic, irregular-shaped lesions develop on the symptomatic canes and rachises. Symptoms on fruit appear as brown, shriveled berries near harvest $(26,28)$. Infections on the canes and rachises weaken the plant and may cause premature fruit drop. Infections on fruit directly decrease yield and fruit quality. The disease is common in the United States and grape-growing regions around the world $(15,18,20,26)$. Up to $30 \%$ loss of the crop has been re-

Corresponding author: L. V. Madden

E-mail: madden.1@osu.edu

Accepted for publication 21 February 2008.

doi:10.1094/PDIS-92-7-1053

(C) 2008 The American Phytopathological Society ported in southern Ohio grape-growing regions (8).

Selective pruning and protective fungicide applications are commonly used in an attempt to control the disease $(26,28)$. Protective fungicides, such as mancozeb or captan, applied on a 7- to 10-day calendarbased schedule, have been the main fungicides for disease management $(7,26)$. Many growers in Ohio initiate the fungicide application schedule when the first few leaves start to expand and shoots are 10 to $20 \mathrm{~cm}$ long (M. A. Ellis, unpublished). Growers wait until that growth stage because it seems uneconomical to apply fungicide onto smaller tissues. However, $P$. viticola becomes active earlier in the growing season, when only about 2.5 $\mathrm{cm}$ of the new growth of the grape tissues has emerged $(5,18,26)$. During this period, the fungus, which had survived winter in previously infected old canes and trunk, produce pycnidia that contain numerous $\alpha$ conidia $(5,31)$. Rain splash of these $\alpha$-conidia onto healthy susceptible tissues (such as newly developed leaves and internodes) may result in new infections early in the season. The close proximity between the source of inoculum and the susceptible tissues also may favor infection in the early growing season. It has been shown that infection is dependent on ambient temperature and wetness duration (9).

Despite the fact that the disease is believed to be very common in Ohio (M. A. Ellis, unpublished), there is no quantitative information about how widely the disease is distributed among the vineyards in the state, the mean disease incidence, and how growers' management practices affect disease incidence. Therefore, objectives of this study were to determine the distribution of the disease in Ohio, and to identify factors associated with incidence of Phomopsis cane and leaf spot of grape in commercial vineyards. A statewide survey was conducted to collect data from growers in different parts of the state over 3 years. The effects of geographical, weather-related, or management-related factors on the disease were examined. A hierarchical linear mixed model (16) was used to quantify the variation in observed disease incidence among different spatial scales. Binary logistic regression model analysis was used to examine potential risks of disease at the vineyard scale in relation to weather and management practices (33).

\section{MATERIALS AND METHODS}

Disease incidence of grape leaves and internodes with Phomopsis cane and leaf spot symptoms was obtained though a statewide survey from 2002 to 2004 in Ohio. Five major regions were selected within the state: A, Northeast; B, Northwest; C, Central-east; D, Central; and E, South (Fig. 1). The regions were defined by the Ohio Wine Production Association. Within each region, two to three commercial farms were selected randomly from a list of known farms, and one to three vineyards were randomly selected within each farm (Table 1). The majority of cultivars examined were French hybrid (Vitis intraspecific hybrid), except for one location with American cultivars (Vitis labrusca). The grown cultivars are all considered susceptible or highly susceptible (7). The cultivar grown in the vineyard was not considered in selecting farms or vineyards.

In each vineyard, disease incidence was assessed on a regularly spaced eight-byeight grid of grapevines, which consisted of the same cultivar. This particular sampling method was used because of a further analysis of spatial pattern of this dis- 
ease (M. Nita, unpublished), which is not discussed in this article. Eight consecutive rows of vines were selected and, within a row, eight consecutive vines were assessed to create the grid. Typically, there was approximately $3 \mathrm{~m}$ between vines within rows and approximately $2 \mathrm{~m}$ between rows. Three shoots per vine were randomly selected within a vine. Within a shoot, the first five leaves and internodes from the base of the shoot were visually assessed for Phomopsis symptoms. When eight consecutive rows were not available for a given cultivar, maximum possible rows

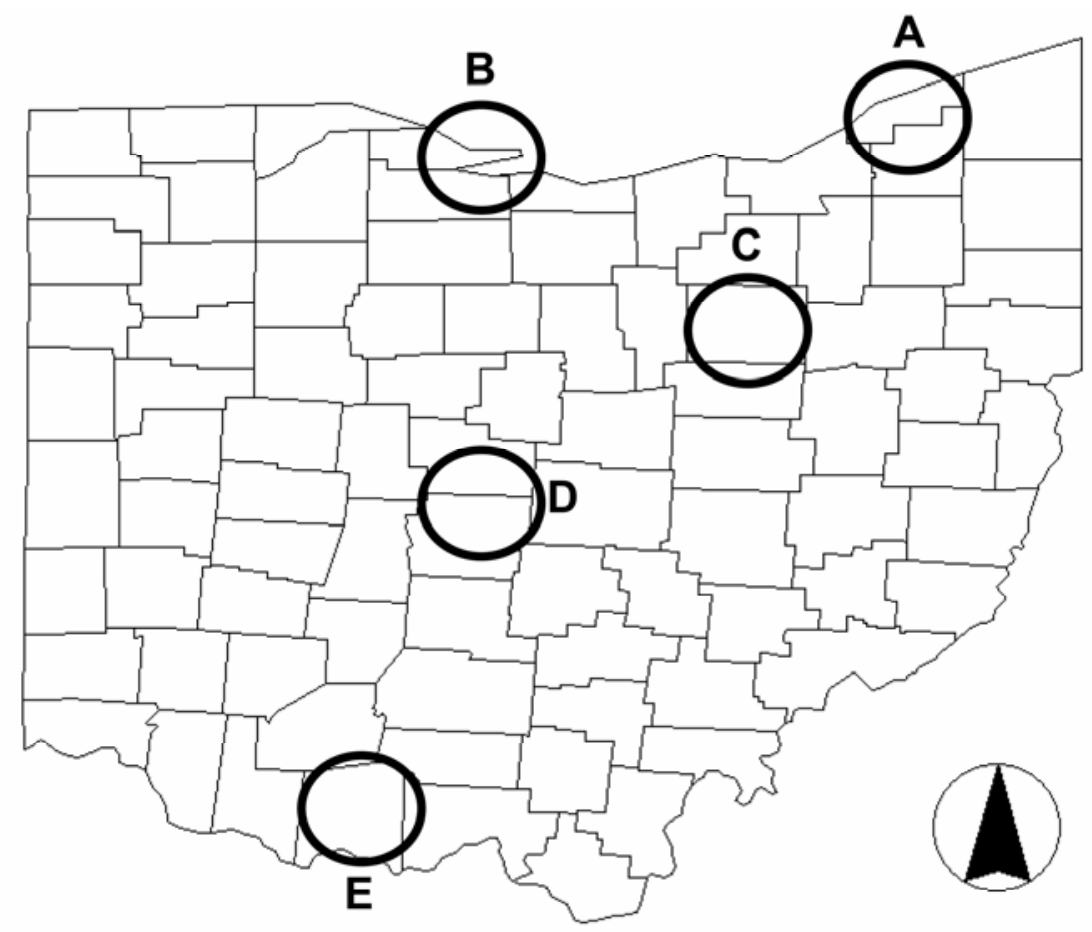

100 0 100

200

300 Kilometers

Fig. 1. Ohio grape-growing regions surveyed in this study (circled): A, Northeast; B, Northwest; C, Central-east; D, Central; and E, South.

were assessed. Assessments of vines were conducted around veraison (or EichhornLorenz stage 35) (26).

Assessment of potential factors: Hierarchical analysis. A hierarchical linear mixed model was used to determine effects of region, farm, vineyard, sampling site (i.e., vine), and shoot on disease incidence. The model used the data that were collected at the lowest spatial hierarchy (internode or leaf within a shoot) to identify higher-level effects in the survey. The model can be written as:

$y=\mu+R+G+V+S+C$

where $y$ is angular transformed disease incidence (i.e., $\arcsin (\sqrt{ }$ proportion $)$, which was selected after comparison with other transformation methods, such as $\log (y)$ ) for leaves or internodes, $R$ is the effect of region, $G$ is the effect of farm ("grower") within a region, $V$ is the effect of vineyard within a farm, $S$ is effect of site (vine) within a vineyard, and $C$ is effect of shoot ("cane") within a site. The model was fitted with PROC MIXED of SAS (v. 9.1; SAS Institute, Cary, NC), using the restricted maximum likelihood method. All variables were considered random-effect factors in the model, except region, which was considered as a fixed-effect factor. The $C$ term is equivalent of the residual. The effect of region was determined with an $F$ test. The random effects were evaluated with $\chi^{2}$ tests based on differences of -2 times the log-likelihoods (which describes a degree of fit) for sequential fits of the model (16). In other words, two models were compared using -2 times the difference of log-likelihood statistics. For exam-

Table 1. Mean disease incidence in percentage (and standard error) of Phomopsis cane and leaf spot of grape per vineyard during 2002 - to 2004 in Ohio for leaves and cane (shoot) internodes ${ }^{\mathrm{a}}$

\begin{tabular}{|c|c|c|c|c|c|c|c|c|}
\hline \multirow[b]{2}{*}{ Region } & \multirow[b]{2}{*}{ Farm $^{\text {b }}$} & \multirow[b]{2}{*}{ Cultivar } & \multicolumn{2}{|c|}{2002} & \multicolumn{2}{|c|}{2003} & \multicolumn{2}{|c|}{2004} \\
\hline & & & Leaf & Node & Leaf & Node & Leaf & Node \\
\hline Central & A & Vignol & $47.5(1.5)$ & $48.9(1.6)$ & $49.3(1.9)$ & $40.4(2.2)$ & $67.7(1.6)$ & $59.3(1.9)$ \\
\hline Central & A & Vidal Blanc & $29.2(1.6)$ & $54.5(1.9)$ & $41.8(2.1)$ & $48.6(2.7)$ & $55.3(2.3)$ & $50.0(2.5)$ \\
\hline Central & A & Chambourcin & - & $19.5(1.7)$ & $20.7(2.1)$ & $40.8(3.4)$ & $50.7(2.2)$ & $44.9(2.6)$ \\
\hline Central & B & Seyval & $50.2(1.9)$ & $61.3(2.2)$ & $66.1(1.4)$ & $46.0(2.4)$ & - & - \\
\hline Central & B & Rayon d'Or & $52.7(1.2)$ & $69.4(1.6)$ & $61.9(1.9)$ & $49.8(2.2)$ & _- & _- \\
\hline Central & B & Catawba & $38.6(1.3)$ & $86.7(1.2)$ & $54.6(1.7)$ & $75.1(2.2)$ & - & - \\
\hline Central & $\mathrm{C}$ & Vidal & $46.5(2.6)$ & $41.3(3.2)$ & $44.2(2.8)$ & $41.0(2.9)$ & $63.2(3.7)$ & $54.3(3.8)$ \\
\hline Central & $\mathrm{C}$ & Chanceller & $65.4(1.9)$ & $65.8(2.3)$ & $60.1(2.4)$ & $66.7(2.4)$ & $89.4(1.3)$ & $90.9(1.6)$ \\
\hline Central & $\mathrm{C}$ & Seyval & $64.4(2.5)$ & $39.2(3.9)$ & $23.8(2.7)$ & $27.3(2.4)$ & $77.8(2.8)$ & $67.4(3.2)$ \\
\hline South & $\mathrm{D}$ & Vidal & $23.0(1.6)$ & $21.8(1.9)$ & $46.5(2.0)$ & $36.3(2.2)$ & $28.4(1.9)$ & $26.4(2.0)$ \\
\hline South & $E^{*}$ & Vidal & $25.4(2.3)$ & $56.0(2.5)$ & $68.6(2.5)$ & $73.9(2.7)$ & $83.1(1.7)$ & $72.3(2.3)$ \\
\hline Northeast & $\mathrm{F}$ & Chardonel & $13.4(1.1)$ & $55.5(2.0)$ & $19.4(1.9)$ & $29.0(2.5)$ & $30.5(1.7)$ & $34.3(2.2)$ \\
\hline Northeast & $\mathrm{F}$ & Cabernet Sauvignon & $4.6(0.7)$ & $12.6(1.3)$ & $9.5(1.0)$ & $3.2(0.7)$ & $20.7(1.5)$ & $16.8(1.4)$ \\
\hline Northeast & $\mathrm{G}^{*}$ & Concord & $7.2(0.9)$ & $15.4(1.8)$ & $21.2(1.4)$ & $15.3(1.3)$ & $30.0(1.6)$ & $36.7(2.0)$ \\
\hline Northwest & $\mathrm{H}$ & Niagra & $18.2(1.4)$ & $59.8(1.7)$ & $32.2(1.8)$ & $34.2(2.1)$ & $57.4(1.4)$ & $92.9(5.5)$ \\
\hline Northwest & I & Concord & $15.5(1.3)$ & $57.0(2.2)$ & $35.0(2.3)$ & $45.3(3.1)$ & $45.4(1.6)$ & $74.8(2.0)$ \\
\hline Northwest & $\mathrm{J}$ & Catawba & 19.9 (1.4) & $73.3(1.9)$ & $24.9(2.0)$ & $23.4(2.0)$ & $41.8(1.4)$ & 83.2 (1.6) \\
\hline Central-east & $\mathrm{K}$ & Clinton & $61.3(3.1)$ & $73.1(2.9)$ & $34.8(2.5)$ & $48.5(3.1)$ & $67.7(2.5)$ & $64.1(2.6)$ \\
\hline Central-east & $\mathrm{K}$ & Clinton & $63.1(2.5)$ & $57.1(3.2)$ & $28.9(2.3)$ & $32.6(2.6)$ & $60.2(2.3)$ & $61.2(2.5)$ \\
\hline Central-east & $\mathrm{K}$ & Reliance & $37.9(2.7)$ & $72.9(2.7)$ & $46.9(2.5)$ & $41.5(2.8)$ & $73.5(2.4)$ & $66.3(2.9)$ \\
\hline Central-east & $\mathrm{K}$ & Ives & $30.0(4.3)$ & $82.5(2.6)$ & $34.6(3.0)$ & 66.7 (4.9) & $60.4(3.4)$ & $65.4(3.2)$ \\
\hline$\ldots$ & $\ldots$ & Overall & $32.8(0.8)$ & $52.0(0.9)$ & $39.6(0.8)$ & $40.2(0.9)$ & $52.7(0.9)$ & $58.3(1.1)$ \\
\hline
\end{tabular}

${ }^{\text {a }}$ Symbol: - indicates missing data.

${ }^{\mathrm{b}}$ Labels for farms. Farm K is an experimental station with no fungicide applied during the season. Asterisk (*) indicates management information not provided. 
ple, to determine the effect of the $S$ term, equation 1 (as written) and a version of equation 1 without $S$ term were fitted to the data and then models were compared using log-likelihoods statistics for the models. If the statistic was greater than 3.84 (corresponding to the upper 95th percentile of the $\chi^{2}$ distribution with 1 degree of freedom), it was concluded that the models were significantly different from each other with $95 \%$ confidence.

Predictor variables using weather and management information. Ambient weather data at an area-wide spatial scale were obtained from Ohio Agricultural Research and Development Center (OARDC) weather station records available online (24). Data from weather stations closest to the surveyed vineyards were used. Distance from weather station to the farm ranged from $3 \mathrm{~km}$ (farm K) to $123 \mathrm{~km}$ (farm E). Both hourly and daily weather information were used to calculate sums, averages, and durations (h) of each specified condition. Data from the beginning of April to the end of June were examined.

There were no previous formal attempts to relate epidemics of Phomopsis cane and leaf spot to weather data, except for predictions of infection for individual inoculation periods (22). Therefore, a range of weather variables available from weather station datasets was taken into consideration. Given the splash dispersal nature of the disease (26) and requirements of leaf wetness and appropriate temperature for infection (9), weather information regarding temperature, rain, and relative humidity (RH; as a substitute for unavailable leaf wetness; 12) were analyzed. All variables were scaled between 0 and 1 by dividing by the observed maximum among regions and years to ensure uniformity of the variable scale. Major weather variables used are described in Table 2.

In addition to weather variables, a model for Phomopsis cane and leaf spot infection
(22) was used to classify weather conditions into two categories for potential predicted infection events (Table 2). The infection model developed by Erincik et al. (9) to predict disease intensity from average temperature $(T)$ and wetness duration $(W)$ during an infection period (defined as wetness event triggered by rain), assuming inoculum was available, is given as:

$z=\alpha \cdot t^{\beta} \cdot(1-t)^{\gamma} \cdot W^{\delta}$

where $z$ is disease intensity (disease severity per internode or number of lesions per leaf $), t=\left(T-T_{\min }\right) /\left(T_{\max }-T_{\min }\right), T_{\min }$ and $T_{\max }$ are assumed minimum $\left(5^{\circ} \mathrm{C}\right)$ and maximum $\left(35.5^{\circ} \mathrm{C}\right)$ temperatures for infection, and $\alpha(=1.8), \beta(=1.5), \gamma(=1.7)$, and $\delta$ $(=1.1)$ are parameters estimated from their controlled-environment experiments and evaluated using inoculation in the field (9).

Because there were no leaf wetness records available in weather-station datasets, hours when RH was above $90 \%$ or there was recorded rainfall were used to estimate leaf wetness durations. When either precipitation was over $0.02 \mathrm{~mm}$ or RH was above $90 \%$, it was assumed (as an approximation) that leaves were wet $(29,32)$. Using equation 2 , predicted infection events were classified into two categories: light infection event $(30>z>60$ lesions per leaf) or moderate infection event $(z>60$ lesions) (22). Predictor variables DL and DM then were defined as the number of light and moderate infection periods, respectively, over the relevant 10-day time window (see below).

Weather data from 1 April to 30 June of each year were considered and various time windows were considered to construct variables. Because this study covers large geographic regions in three different years, and disease assessment was done only once per year, variables based on a very short time window (such as a day) may not be suitable, and a long time window (such as a month) would lose resolution. Various time-window options were considered and 7-day and 10-day time windows were compared in detail (M. Nita, data not shown) Based on overall fit and accuracy of risk models, 10-day time windows from the beginning of April to the end of June were created ( 1 to 10 April, 11 to 20 April,...21 to 30 June). Weather-based variables (either direct, such as mean RH, or indirect, such as DM; 9) were calculated based on these time windows. For example, average temperature (T) of 1 to 10 April was calculated by averaging hourly temperature over 10 days.

Other factors considered as potential predictor variables included age of vineyards, cultivar, and fungicide application records obtained from growers (Table 2, management variables). Growers provided information on fungicide applications and other management practices each year. Based on the records, the sum of days with effective fungicide coverage was estimated for each vineyard (over the relevant time window) assuming that a protectant fungicide application was effective for 10 days after a spray. Only fungicides considered to be effective against $P$. viticola were included $(7,26,28)$. This variable was also scaled between 0 and 1 by dividing by 10 , which is assumed maximum days with fungicide coverage. Pruning practice also can be an important management factor; however, most vineyards had a single-curtain (high cordon) training system, and only a few vineyards had an umbrella kniffin system. Thus, with insufficient variation across the state, pruning practice was not included as a management variable.

Also, although disease incidence on both leaves and internodes was collected, only the dataset from internode assessment was used for analyses of disease risk in relation to weather and other variables.

Stepwise logistic regression models. Because the economic threshold or eco-

Table 2. Some potential predictor variables considered in the development of risk models for Phomopsis cane and leaf spot of grape on leaves and cane internodes in commercial vineyards in Ohio over 3 years

\begin{tabular}{ll}
\hline Symbol & \\
\hline Weather variable & Description \\
PPTS & Sum of precipitation (mm) \\
PPTD & Sum of days with precipitation (day) \\
PPTH & Sum of hours with precipitation (h) \\
T & Average temperature $\left({ }^{\circ} \mathrm{C}\right)$ \\
RH & Average relative humidity $(\%)$ \\
RH70 & Sum of hours with RH $>70 \%$ \\
RH90 & Sum of hours with RH $>90 \%$ \\
Infection model variable & Sum of predicted low (or higher) infection events \\
DL & Sum of predicted moderate (or higher) infection events \\
DM & \\
Management variable & Sum of days with fungicide coverage, based on the assumption that a protectant fungicide provides coverage for 10 days \\
C & Dormant application of fungicide $(0$ if not used, 1 if used) \\
DOR & Risk indicator variable. D20 $=1$ if observed disease incidence $>20 \%$, and 0 otherwise \\
Risk indicator variable & Risk indicator variable. D40 $=1$ if observed disease incidence $>40 \%$, and 0 otherwise \\
D20 & \\
D40 & Age of vineyard (years) \\
Others & \\
AGE & \\
\hline
\end{tabular}


nomic injury level of this disease is not known, two somewhat arbitrary thresholds of incidence were used to indicate a relatively high incidence of Phomopsis leaf and cane spot. Thresholds were set to either 40 or $20 \%$ disease incidence on internodes per vineyard. Thus, two disease variables were defined: D20 and D40. D20 $=1$ if mean incidence per vineyard was above $20 \%$ and D20 $=0$ otherwise; D40 = 1 if mean incidence per vineyard was above $40 \%$ and D40 $=0$ otherwise. These are arbitrary scenarios for potential disease management goals, and the two scenarios were examined separately in the analyses. For analysis purposes, incidence above $40 \%$ can be considered relatively poor control of the disease. Conversely, incidence below $40 \%$ (and even more so, below 20\%) can be considered as an adequate control of the disease.

Weather and other predictor variables constructed were examined for their association with disease risk variables (D20 and D40) using nonparametric correlation coefficients. Kendall's correlation coefficient (Kendall's "tau") was calculated for the relation between each predictor variable and D20 and D40, using PROC CORR of SAS, and these results were used for initial selection of variables prior to the further analysis. An achieved significance level $(\mathrm{P})$ of $<0.1$ for a correlation was used as a guideline for subsequent variable selection. High positive correlation to D20 or D40 is indicative of a variable that favors an epidemic and high negative correlation indicates a variable unfavorable for an epidemic (and, thus, for better management).

Binary logistic regression analysis was used to model the relationship between D20 or D40 and different potential predictor variables. The dependent variable for logistic regression is binary (i.e., above or below the threshold of disease incidence) with assumed binomial distribution. A logistic model can be written as a linear combination of predictor variables, specifically:

$\ln \left(\frac{p}{1-p}\right)=p^{*}=\beta_{0}+\beta_{1} X_{1}+\beta_{2} X_{2}+\beta_{3} X_{1} X_{2}+\ldots$

where $p$ is the probability that D20 $=1$ or $\mathrm{D} 40=1, p *$ is the logit of $p, X_{1}, X_{2}$ (and so on) are predictor variables, and $\beta_{1}, \beta_{2}$ (and so on) are parameters (coefficients). $p$ can be obtained by back-transformation of the $\operatorname{logit}\left(p=1 /\left[1+\exp \left(-p^{*}\right)\right]\right)$. If predicted $p$ is greater than 0.5 , a high risk (e.g., $\mathrm{D} 40=1$ or D20 = 1) is predicted. Because logistic models predict the risk of disease, they can be considered as risk assessment models.

In a preliminary step, the stepwise variable-selection method in PROC LOGISTIC of SAS was used to identify those variables or combinations of variables with the ability to discriminate between lowand high-risk cases. The collection of variables under consideration included those with moderate or higher Kendall correlation coefficients. Several different pools of predictor variables were considered in this initial variable-screening step. In particular, models were constructed for (i) just the weather variables, (ii) just the infectionmodel (9) variables, (iii) just the management variables, (iv) just the weather and management variables, and (v) just the infection-model and management variables. The variables most consistently related to disease risk in the different models then were utilized to fit several "final" logistic models for both D40 and D20. Maximum likelihood was used to fit each model, and the criterion for variable inclusion was a significance level of 0.1 or less (i.e., $P<0.1)$ for the estimated parameter ( $\beta_{1}, \beta_{2}$, and so on). Models with a single variable, multiple variables, and interaction of variables were examined.

Overall accuracy was determined by calculating the percentage of all cases (vineyards) where observation and prediction agreed (regarding D40 and D20). Two other forms of accuracy were determined: sensitivity and specificity. Sensitivity is the percentage of high-risk cases (i.e., D20 or $\mathrm{D} 40=1$ ) correctly predicted. Specificity is the percentage of low-risk cases (i.e., D20 or D40 $=0$ ) correctly predicted (17). Also, area under the receiver operating characteristic (ROC) curve, which is another measurement of accuracy, also was estimated for each model. A ROC curve is a

Table 3. Test statistics for the effect of region $(R)$, farm within region $(G)$, vineyard within farm $(V)$, and site (i.e., vine) within farm $(S)$ on incidence of Phomopsis cane and leaf spot of grape on leaves and cane internodes in Ohio over 3 years based on a hierarchical linear mixed model

\begin{tabular}{lcccc}
\hline Disease, year & $\boldsymbol{R}^{\mathbf{a}}$ & $\boldsymbol{G}^{\mathbf{b}}$ & $\boldsymbol{V}^{\mathbf{b}}$ & $\boldsymbol{S}^{\mathbf{b}}$ \\
\hline Leaves & & & & \\
2002 & 3.20 & $342.2^{*}$ & $524.0^{*}$ & $202.1^{*}$ \\
2003 & 3.64 & $212.2^{*}$ & $253.8^{*}$ & $279.1^{*}$ \\
2004 & 1.42 & $475.2^{*}$ & $122.2^{*}$ & $285.4^{*}$ \\
Internodes & & & & \\
2002 & 1.34 & $585.3^{*}$ & $277.3^{*}$ & $262.5^{*}$ \\
2003 & 3.44 & $206.2^{*}$ & $247.0^{*}$ & $276.4^{*}$ \\
2004 & 3.23 & $307.2^{*}$ & $180.0^{*}$ & $213.3^{*}$ \\
\hline
\end{tabular}

${ }^{\text {a }} F$ statistic (not significant; $P \geq 0.05$ ).

${ }^{\mathrm{b}}$ Likelihood ratio statistic: based on a difference of log-likelihood statistics between models, where a larger positive value indicates significant reduction of fit to the data. Asterisks indicate significant effect $(P \leq 0.05)$ based on a $\chi^{2}$ test. plot of the sensitivity against 1 - specificity $(10,13,17,30)$. An area under ROC curve closer to 1 represents a more accurate model, whereas an area closer to 0.5 shows a less accurate model $(13,17,30)$. In addition, max-rescaled $R^{2},-2$ times loglikelihood $(-2 l l)$, and standard errors for each estimated parameter also were calculated.

\section{RESULTS}

During 2002, 20 different vineyards from 11 different farms were evaluated for leaf and internode disease incidence. The mean disease incidence per vineyard (an eight-by-eight grid of vines within a farm) varied from 5 to $87 \%$, and the mean disease incidence across all the vineyards was 33 and $52 \%$ for leaves and internodes, respectively (Table 1). In 2003, the same number of vineyards was assessed, and the mean disease incidence per vineyard varied from 3 to $75 \%$ (across leaves and internodes). The mean disease incidence across all the vineyards was $40 \%$ for both leaves and internodes.

In 2004, 16 and 17 vineyards were assessed for leaf and internode disease incidence, respectively, from 10 different farms. The number of vineyards and farms decreased due to a renovation of vineyards by one farm. The mean disease incidence per vineyard varied from 17 to $93 \%$ (across leaves and internodes) and the mean disease incidence for all was $53 \%$ for leaves and $58 \%$ for internodes. Thus, the disease was found in all vineyards surveyed in all years, with a wide range of disease incidence observed over the 3 years. Although 2004 had relatively higher overall disease, there was no obvious overall increase or decrease in disease incidence over the 3 years (Table 1 ).

Hierarchical analysis. Results from a linear mixed model indicated that disease incidence was significantly affected $(P<$ $0.05)$ by farm within region $(G)$, vineyard within farm $(V)$, and site within vineyard $(S)$ (see equation 1; Table 3). There was higher variance in transformed disease incidence among shoots within sites than among sites (within vineyards), vineyards (within farms), or farms (within regions) (Table 4). However, regions $(R)$ were not significantly different (Table 3 ), indicating that incidence of disease did not systematically vary across the state. Thus, smaller spatial scale factors such as local weather conditions, landscape, specific management methods, or location of initial inoculum were likely the source of variations.

Preliminary evaluation of predictor variables. Kendall correlation coefficients were obtained between calculated variables over different time periods (time windows) and risk index variables (D20 or D40). In general, analysis of weather variables showed only a few significantly high correlation coefficients. Variables consisting of only precipitation measurements, as 
the sum of precipitation (PPTS), hours of precipitation (PPTH), days with precipitation (PPTD), showed only two cases (PPTD in 11 to 20 May for D40, and PPTS in 1 to 10 June for D20 model) with a correlation coefficient high enough to be significant $(P<0.1)$ (Table 5, partial results).

Average temperature was significant $(P$ $<0.1$ ) for the 21 to 30 May and 10 to 20 June time windows for the D40 risk variable and for the 1 to 10 April, 1 to 10 May, and 10 to 20 June time windows for the D20 risk variable (Table 5). Average RH was only significant for the 11 to 20 May time window for both D40 and D20 risk variables; hours of RH over 70\% (RH70) was significant for the 1 to 10 April and 1 to 10 May time windows for D40 and the 1 to 10 April and 11 to 20 May time windows for D20, and hours of RH over $90 \%$ (RH90) was significant only for the 21 to 30 May time window for both risk variables (Table 5, partial results). The predictive infection-model variable DL was significant for the 21 to 30 April, 11 to 21 May, 11 to 20 June, and 21 to 31 June time windows for D40 and the 11 to 21 May and 21 to 31 June time window for D20. For both D40 and D20, the infectionmodel-based DM variable was significant only for the 11 to 20 May time window (Table 5). However, this correlation coefficient was the highest found in the analyses for the weather variables. The lack of very high correlations between risk indicator variables and weather-related variables

Table 4. Estimated variances from hierarchical linear mixed models for farm within region $\left(\sigma_{G}^{2}\right)$, vineyard within farm $\left(\sigma_{V}^{2}\right)$, site (i.e., vine) within vineyard $\left(\sigma_{S}^{2}\right)$, and cane (i.e., shoot) within site $\left(\sigma_{C}^{2}\right)$ for incidence of Phomopsis cane and leaf spot of grape on leaves in internodes in Ohio over 3 years ${ }^{\mathrm{a}}$

\begin{tabular}{lcccc}
\hline Disease, year & $\sigma_{G}^{2}$ & $\sigma_{V}^{2}$ & $\sigma_{S}^{2}$ & $\sigma_{C}^{2}$ \\
\hline Leaves & & & & \\
2002 & 0.008 & 0.020 & 0.012 & 0.033 \\
2003 & 0.005 & 0.012 & 0.020 & 0.041 \\
2004 & 0.028 & 0.007 & 0.018 & 0.031 \\
Internodes & & & & \\
2002 & 0.024 & 0.017 & 0.022 & 0.049 \\
2003 & 0.001 & 0.022 & 0.027 & 0.057 \\
2004 & 0.016 & 0.013 & 0.020 & 0.043 \\
\hline
\end{tabular}

${ }^{a}$ Incidence based on angular transformation.

Table 5. Kendall correlation coefficients $(K \mathrm{~s})$ between indicator variables (D20 and D40) and some weather or management variables examined for the risk of Phomopsis cane and leaf spot of grape on leaves and cane internodes in Ohio over 3 years

\begin{tabular}{|c|c|c|c|c|c|c|}
\hline \multirow[b]{2}{*}{ Date $^{b}$} & \multirow[b]{2}{*}{ Predictor $^{c}$} & \multicolumn{2}{|c|}{ Indicator variable $^{\mathbf{a}}$} & \multirow[b]{2}{*}{ Predictor $^{c}$} & \multicolumn{2}{|c|}{ Indicator variable $^{\mathbf{a}}$} \\
\hline & & D40 & D20 & & D40 & D20 \\
\hline 1-10 April (A1) & PPTS & $-0.19(0.10)$ & $-0.09(0.45)$ & DM & $-0.08(0.58)$ & $0.13(0.36)$ \\
\hline 11-20 April (A2) & & $-0.09(0.44)$ & $-0.19(0.10)$ & & $0.09(0.47)$ & $0.01(0.96)$ \\
\hline 20-30 April (A3) & & $-0.08(0.48)$ & $-0.13(0.27)$ & & $0.11(0.43)$ & $0.05(0.71)$ \\
\hline 1-10 May (M1) & & $-0.11(0.34)$ & $0.16(0.18)$ & & $-0.03(0.83)$ & $0.16(0.19)$ \\
\hline 11-20 May (M2) & & $0.06(0.61)$ & $0.04(0.74)$ & & $0.31(0.01)$ & $0.33(0.01)$ \\
\hline 21-31 May (M3) & & $-0.10(0.38)$ & $-0.14(0.22)$ & & $-0.02(0.87)$ & $-0.08(0.51)$ \\
\hline 1-10 June (J1) & & $0.14(0.24)$ & $0.22(0.06)$ & & $-0.04(0.73)$ & $-0.09(0.47)$ \\
\hline 11-20 June (J2) & & $0.06(0.59)$ & $0.02(0.89)$ & & $0.16(0.18)$ & $0.20(0.10)$ \\
\hline 21-30 June (J3) & & $0.07(0.56)$ & $0.12(0.29)$ & & $0.10(0.42)$ & $0.04(0.75)$ \\
\hline 1-10 April (A1) & $\mathrm{RH}$ & $-0.18(0.13)$ & $-0.15(0.21)$ & $\mathrm{C}$ & NA & NA \\
\hline 11-20 April (A2) & & $0.02(0.87)$ & $-0.03(0.80)$ & & NA & NA \\
\hline 20-30 April (A3) & & $0.15(0.20)$ & $-0.01(0.93)$ & & $-0.40(<0.01)$ & $-0.51(<0.01)$ \\
\hline 1-10 May (M1) & & $-0.16(0.17)$ & $0.02(0.87)$ & & $-0.50(<0.01)$ & $-0.56(<0.01)$ \\
\hline 11-20 May (M2) & & $0.27(0.02)$ & $0.23(0.05)$ & & $-0.40(<0.01)$ & $-0.30(0.02)$ \\
\hline 21-31 May (M3) & & $0.03(0.81)$ & $-0.07(0.53)$ & & $-0.36(<0.01)$ & $-0.18(0.14)$ \\
\hline 1-10 June (J1) & & $0.09(0.46)$ & $0.00(0.98)$ & & $-0.32(0.01)$ & $-0.20(0.09)$ \\
\hline 11-20 June (J2) & & $0.10(0.38)$ & $0.09(0.45)$ & & $-0.23(0.06)$ & $-0.18(0.18)$ \\
\hline 21-30 June (J3) & & $0.05(0.68)$ & $-0.11(0.34)$ & & $-0.34(<0.01)$ & $-0.42(<0.01)$ \\
\hline 1-10 April (A1) & $\mathrm{T}$ & $0.16(0.18)$ & $0.25(0.03)$ & DOR & $-0.51(<0.01)$ & $-0.72(<0.01)$ \\
\hline 11-20 April (A2) & & $0.03(0.77)$ & $0.06(0.59)$ & AGE & $0.06(0.61)$ & $0.23(0.05)$ \\
\hline 20-30 April (A3) & & $0.12(0.30)$ & $0.19(0.10)$ & & $\ldots$ & $\ldots$ \\
\hline 1-10 May (M1) & & $0.12(0.32)$ & $0.24(0.04)$ & & $\ldots$ & $\ldots$ \\
\hline 11-20 May (M2) & & $0.12(0.30)$ & $0.15(0.21)$ & & $\ldots$ & $\ldots$ \\
\hline 21-31 May (M3) & & $0.20(0.09)$ & $0.11(0.36)$ & & $\ldots$ & $\ldots$ \\
\hline $1-10$ June $(\mathrm{J} 1)$ & & $0.10(0.38)$ & $0.05(0.64)$ & & $\ldots$ & $\ldots$ \\
\hline 11-20 June (J2) & & $0.21(0.07)$ & $0.21(0.07)$ & & $\ldots$ & $\ldots$ \\
\hline 21-30 June (J3) & & $-0.06(0.63)$ & $-0.01(0.93)$ & & $\ldots$ & $\ldots$ \\
\hline
\end{tabular}

${ }^{\text {a }}$ D $40=1$ if mean incidence per vineyard $>40 \%$ and 0 otherwise. D20 $=1$ if mean incidence per vineyard $>20 \%$ and 0 otherwise. Numbers in parentheses are significance levels for correlation coefficients; $\mathrm{NA}=$ not applicable.

${ }^{\mathrm{b}}$ Letters in parentheses are used as a subscript of variables to identify time range.

${ }^{\mathrm{c}}$ Predictor variables: PPTS $=$ sum of precipitation, $\mathrm{DM}=$ sum of predicted moderate (or higher) infection events, $\mathrm{RH}=$ relative humidity, $\mathrm{C}=$ sum of days with fungicide coverage, $\mathrm{T}=$ average temperature, $\mathrm{DOR}=$ dormant application of fungicide, and Age $=$ age of vineyard. 
and the average vineyard age was 31 years, with the youngest vineyard being 10 years old. Considering that disease was found in all vineyards surveyed, there appeared to have been sufficient time to distribute $P$. viticola throughout the vineyards.

Binary logistic regression. Following the initial screening of potential predictor variables based on Kendall correlation coefficients, several logistic models were obtained using the stepwise variable-selection procedure in PROC LOGISTIC of SAS. It is well established that stepwise regression methods alone should be used only to identify potential subsets of predictor variables and not to derive a single final model (1). There may be alternative models with slightly different combinations of variables that result in high accuracy on the current or similar datasets, or which are more logical in terms of current understanding of the system. In the screening of predictor variables in the preliminary stepwise logistic analyses, management and weather variables during early May (M1: 1 to 10 May) and mid-May (M2: 11 to 21 May) were found to be most associated with D20 or D40. Furthermore, some weather variables (e.g., RH90) were eliminated because of their high correlation (or multicollinearity) with other predictor variables. Thus, a set of final models was developed for the M1 and M2 time windows separately and then together, with or without the variable for dormant application of fungicide (DOR) (Table 6).

D40 risk models tended to have lower $R^{2}$ (36 to $45 \%$ ) compared with D20 risk models (where $R^{2}$ was 43 to $65 \%$ ). All models resulted in relatively high sensitivity ( 88 to $98 \%$ high-risk cases were correctly classified) and moderate to high specificity (45\% to $89 \%$ of low-risk cases were correctly classified). D40 models tended to have a little lower overall accuracy ( 72 to $80 \%$ ) than D20 models ( 87 to $91 \%$ ). Area under ROC curves varied from 0.75 to 0.97 . As with $R^{2}$ and accuracy, D20 models also had relatively larger area under ROC curves (0.85 to 0.97) compared with D40 models (0.75 to 0.85 ).

Without inclusion of the DOR variable, coverage of fungicide in early and midMay $\left(\mathrm{C}_{\mathrm{M} 1}\right.$ and $\left.\mathrm{C}_{\mathrm{M} 2}\right)$ and predicted number of moderate infection events (DM) in midMay $\left(\mathrm{DM}_{\mathrm{M} 2}\right)$ were key factors for both D40 and D20 risk variable models (Table 6). Because the response variable in the model is a high disease risk (disease incidence either $>40 \%$ [D40] or $>20 \%$ [D20]), positive parameter values for $\mathrm{DM}_{\mathrm{M} 1}$ and $\mathrm{DM}_{\mathrm{M} 2}$ indicated that increasing number of moderate infection events (9) in a time window was positively associated with increasing risk of disease. Likewise, negative parameter values for $\mathrm{C}_{\mathrm{M} 1}$ and $\mathrm{C}_{\mathrm{M} 2}$ (Table 6) indicated that applying a fungicide during these time windows was negatively associated with high disease risk (so that applying a fungicide during these times was associated with lower risk of disease). Adding other variables to the logistic model did not improve the model fit. When DOR was added to the collection of variables for possible inclusion in the risk model, only DOR was selected by the stepwise logistic regression procedure for D20-based models (i.e., only DOR was significant; Table 6). On the other hand, D40-based models selected both $\mathrm{C}_{\mathrm{M} 2}$ and DOR with the 11 to 20 May time window (model B), and use of DOR did not improve accuracy of models which considered other time windows. Incorporation of the interaction (product) of predictor variables in the logistic models showed that interaction terms were not significant (i.e., they did not meet the criterion for inclusion of a term into the model) and, hence, did not improve the accuracy of any model.

Based on the results, a "generic" logistic model was developed for both D40 and D20 (Table 6). Variables included in the model were mid-May predicted moderate infection events $\left(\mathrm{DM}_{\mathrm{M} 2}\right)$, early-May fungicide coverage $\left(\mathrm{C}_{\mathrm{M} 1}\right)$, and dormant application of fungicide (DOR) for both D40 and $\mathrm{D} 20$. The reasonable $R^{2}$ values and accuracies achieved by these generic models (Table 6) confirmed the importance of environmental and management factors during this time period for development of the disease.

\section{DISCUSSION}

Phomopsis cane and leaf spot of grape has been known to be present in Ohio's commercial vineyards for many years (M. A. Ellis, unpublished), either by this name or as a component of the "dead-arm disease" complex of grape, which is caused by either $P$. viticola or Eutypa lata (2). Through a statewide survey and use of various statistical methods, disease incidence of Phomopsis cane and leaf spot on grape in commercial vineyards in Ohio and

Table 6. Binary logistic regression models developed for predicting Phomopsis cane and leaf spot risks (D40 or D20) using predictive variables during either 1 to 10 May, 11 to 20 May, or both, with predictive variable for use of fungicide spray during dormant (DOR), shown with overall prediction accuracy, sensitivity, specificity, and area under receiver operating characteristic (ROC) curves (0 to 1)

\begin{tabular}{|c|c|c|c|c|c|c|c|}
\hline Variables $^{\mathbf{a}}$ & $\begin{array}{l}\text { Time } \\
\text { period }\end{array}$ & Model name and equation ${ }^{b}$ & $\begin{array}{c}\text { Max-rescaled } \\
R^{2}\end{array}$ & $\begin{array}{c}\text { Overall } \\
\text { accuracy }(\%)^{\mathrm{c}}\end{array}$ & $\begin{array}{l}\text { Sensitivity } \\
(\%)^{\mathrm{d}}\end{array}$ & $\begin{array}{c}\text { Specificity } \\
(\%)^{\mathrm{e}}\end{array}$ & $\begin{array}{l}\text { Area under } \\
\text { ROC }\end{array}$ \\
\hline \multicolumn{8}{|l|}{ D40 } \\
\hline \multirow[t]{3}{*}{ w/o DOR } & 1-10 May & A: $1.3-5.7 \mathrm{C}_{\mathrm{M} 1}$ & 35.5 & 79.6 & 91.2 & 60.0 & 0.75 \\
\hline & 11-20 May & B: $-0.1+4.9 \mathrm{DM}_{\mathrm{M} 2}-3.0 \mathrm{C}_{\mathrm{M} 2}$ & 40.3 & 79.6 & 88.2 & 65.0 & 0.83 \\
\hline & Both & C: $0.2-3.1 \mathrm{DM}_{\mathrm{M} 2}-5.5 \mathrm{C}_{\mathrm{M} 2}$ & 42.7 & 77.8 & 91.2 & 55.0 & 0.84 \\
\hline \multirow{3}{*}{ with DOR } & 1-10 May & D: $1.3-5.7 \mathrm{C}_{\mathrm{M} 1}$ & 35.5 & 79.6 & 91.2 & 60.0 & 0.75 \\
\hline & 11-20 May & E: $0.2+4.0 \mathrm{DM}_{\mathrm{M} 2}-2.1 \mathrm{C}_{\mathrm{M} 2}-1.7 \mathrm{DOR}$ & 45.3 & 72.2 & 88.2 & 45.0 & 0.85 \\
\hline & Both & $\mathrm{F}: 0.2-3.1 \mathrm{DM}_{\mathrm{M} 2}-5.5 \mathrm{C}_{\mathrm{M} 2}$ & 42.7 & 77.8 & 91.2 & 55.0 & 0.84 \\
\hline Generic & Both & G: $0.2+3.1 \mathrm{DM}_{\mathrm{M} 2}-4.5 \mathrm{C}_{\mathrm{M} 1}-0.6 \mathrm{DOR}$ & 42.9 & 74.1 & 91.2 & 45.0 & 0.84 \\
\hline \multicolumn{8}{|c|}{ - } \\
\hline \multirow[t]{3}{*}{ w/o DOR } & 1-10 May & $\mathrm{H}: 2.2+5.3 \mathrm{DM}_{\mathrm{M} 1}-8.9 \mathrm{C}_{\mathrm{M} 1}$ & 61.8 & 90.7 & 93.3 & 77.8 & 0.91 \\
\hline & 11-20 May & I: $1.2+7.4 \mathrm{DM}_{\mathrm{M} 2}-3.7 \mathrm{C}_{\mathrm{M} 2}$ & 42.5 & 88.9 & 97.8 & 44.4 & 0.85 \\
\hline & Both & $\mathbf{J}: 2.2+5.3 \mathrm{DM}_{\mathrm{M} 1}-8.9 \mathrm{C}_{\mathrm{M} 1}$ & 61.8 & 90.7 & 93.3 & 77.8 & 0.91 \\
\hline \multirow[t]{3}{*}{ with DOR } & 1-10 May & K: $3.7-4.4 \mathrm{DOR}$ & 60.3 & 90.4 & 91.1 & 88.9 & 0.90 \\
\hline & 11-20 May & L: $3.7-4.4 \mathrm{DOR}$ & 60.3 & 90.4 & 91.1 & 88.9 & 0.90 \\
\hline & Both & M: $3.7-4.4 \mathrm{DOR}$ & 60.3 & 90.4 & 91.1 & 88.9 & 0.90 \\
\hline Generic & Both & $\mathrm{N}: 2.5+3.8 \mathrm{DM}_{\mathrm{M} 2}-1.1 \mathrm{C}_{\mathrm{M} 1}-3.7 \mathrm{DOR}$ & 64.7 & 87.0 & 91.1 & 66.7 & 0.97 \\
\hline
\end{tabular}

${ }^{a}$ Risk indicator variables: D40 $=1$ if mean incidence per vineyard $>40 \%$ and 0 otherwise, and D20 $=1$ if incidence $>20 \%$ and 0 otherwise. Predictive variables: w/o DOR included average temperature, relative humidity, sum of predicted moderate (or higher) infection events (DM), and sum of days with fungicide coverage (C) variables for consideration; with DOR included variables in w/o DOR plus dormant application of fungicide (DOR); and the Generic model was developed with consideration of host and pathogen biology. The binary logistic regression model used is shown in equation 3 and description of variables is listed in Table 2.

${ }^{\mathrm{b}}$ Bold letters indicates model name. Model variables were rescaled before analyses by dividing by the maximum observed value. Subscript shows different time windows described: M1 = 1-10 May and M2 = 11-20 May.

${ }^{c}$ Percentage of correctly classified cases (either high or low risk).

${ }^{\mathrm{d}}$ Percentage of correctly classified high risk cases (where observed D40 or D20 $=1$ ).

e Percentage of correctly classified low risk cases (where observed D40 or D20 $=0$ ). 
potential factors that influence disease incidence were examined. Overall, Phomopsis cane and leaf spot on grape was found in all surveyed vineyards, with relatively high mean incidence on leaves (about 42\%) and internodes (about 50\%) over 3 years. The omnipresence of diseased leaves and internodes, and observed high disease incidence in many of the surveyed vineyards, suggest that there is probably sufficient inoculum to have major epidemic outbreaks when environmental conditions are favorable to the disease. It also suggests that disease management practiced in many vineyards is still insufficient for satisfactory control of the disease.

The hierarchical mixed model was used to investigate sources of variation in the observed disease incidence (on a transformed [angular] scale). Results showed that variation in disease incidence was greatest in the lowest strata, that is, shoots (canes) within sites (vines) (Table 4). Moreover, region did not affect disease incidence in the state $(P>0.05$; Table 3$)$. Number of farms per region was relatively small, yet the sample size was high enough to detect significant variation among farms and among vineyards within farms (as well as at lower scales). Moreover, results were consistent over 3 years. In some other surveys of plant diseases, regional variability of disease has been found. For example, the variability in the prevalence of Sclerotinia stem rot of soybean (19) was explained by observed weather patterns. With our study, variations in observed disease incidence were not related to region. This means that any particular region did not have consistently higher or lower disease within each of the 3 years; moreover, any region could have a vineyard with high (or low) disease incidence. Thus, large-scale factors such as climate and landscape probably were not strongly affecting disease incidence. One of potential reasons for the regional results may be related to the intensive management scheme for grape production in Ohio in general. Because of the high influence of early fungicide applications on disease, any regionallevel effects attributable to landscape or climate may be masked. However, based on the significant variation in disease at lower spatial scales, there was evidence that smaller-scale factors such as local weather patterns, cultivars, soil conditions, location of inoculum, amount of inoculum per vineyard, and disease management practices could be affecting Phomopsis disease incidence.

For the examination of potential factors that could contribute to the variation of disease incidence observed, nonparametric correlation analysis and logistic regression analysis were conducted. Correlation analysis (Kendall's "tau") was used to identify potential factors that influence disease incidence, and the logistic regression was used to create models that predict risk of epi- demic based on these factors. Only data on internodes were used for this portion of the analysis, because natural defoliation of older leaves is common, so that the dataset may not represent the full extent of the disease development on foliage (diseased leaves may have been "lost" by the time of the single assessment). Moreover, infection on the internodes can be critical to grape production because of potential crop loss due to broken canes with fruit and flowers, or because of long-term effects when infected canes become the source of inoculum in coming seasons $(26,27)$.

In addition to variables that were directly based on weather and fungicide application records, a predicted-infection model for Phomopsis cane and leaf spot (9) was used to construct and evaluate additional variables in the risk models. The original infection model was designed to predict disease severity with a fixed amount of inoculum; however, the amount of inoculum in vineyards was unknown. Thus, the output of the model ( $z$ in equation 2) was categorized into two relative values, number of low (DL) or moderate (DM) predicted infection events. Because leaf wetness duration was not measured, number of hours with either RH over $90 \%$ or measured rainfall was used as an approximation of leaf wetness duration in the infection model $(29,32)$. More sophisticated and accurate models to estimate leaf wetness are available; however, these require other weather measurements, or measurements recorded on different spatial or temporal scales, that were not available at the locations of interest $(3,4,11,14)$. Although the use of duration of $\mathrm{RH}>90 \%$ adds an additional level of variability to the prediction of disease risk, the risk of disease could still be predicted with relatively high accuracy using DM in models (Table 6). We anticipate that direct measurement of wetness duration within vineyards in the future could result in more accurate models.

Prior to Kendall correlation calculation and the development of logistic regression models, mean incidence per vineyard was classified into categories (D20 and D40) in order to directly relate potential predictor variables to disease risk. This was partly because disease incidence on a percentage scale had substantial variation within and among vineyards (Table 4). Similar analytical approaches, for instance, have been taken for the risk of gray leaf spot of maize (25) and Fusarium head blight of wheat (6). The reason to have two disease-risk thresholds (D40 and D20) was that there was no clear evidence on the relation between degree of cane infection and either yield or long-term health of vines. D40 = 1 can be considered a situation where unsatisfactory level of control is achieved, and D20 $=0$ represents a very low-risk scenario, where successful disease management is achieved.
Result from Kendall correlation and logistic regression model development showed that variables identified by logistic regression analysis were generally the ones with relatively high Kendall correlation coefficients with risk indicators D20 and D40. Higher RH in mid-May, larger number of predicted moderate infection events (DM) in mid-May, fungicide coverage (C) during early or mid-May, and dormant application of fungicide (DOR) were the main factors associated with the disease risk. In general, high RH and large DM in mid-May had positive effects on the observed disease incidence, and $\mathrm{C}$ in midMay and DOR had negative effects. In the logistic models, RH variables were not selected because of their high correlation with other weather variables in the models.

Variables that were based directly and fully on measured precipitation were not significantly related to risk, either based on correlations or on the binary logistic regression. This may appear in conflict with previous studies where the importance of precipitation in disease development was noted $(9,28)$. However, the DM variable, which was significant, is based on duration of time with either RH $>90 \%$ or measured precipitation (coupled with temperature during the high-moisture period). Thus, precipitation was shown to affect disease risk, but in a complex manner. A reason for the apparent lack of direct effect of precipitation alone is that rainfall is highly variable spatially, and the distance between the weather stations and the vineyards may have precluded finding a stronger link between this weather variable and disease risk.

Relatively high accuracy (both sensitivity and specificity) and large area under ROC curves for the D20 models without the DOR variable (models $\mathrm{H}$, I, and $\mathrm{J}$ ) indicates that achieving good fungicide coverage (of the protectant types used by growers in Ohio) early in the season (either 1 to 10 May or 11 to 20 May) is critical in order to keep disease incidence below $20 \%$ (i.e., to achieve $\mathrm{D} 20=0$ ). Also, previous studies indicated the importance of earlyseason application of fungicides for control of the disease $(27,28)$. Grape growth in Ohio generally initiates in late April, and growth is vigorous during the first 2 to 3 weeks of a growing season. P. viticola sporulates greatly in early spring (5), and grape tissues are most susceptible when young (8). Thus, a relatively strong influence of moisture and predicted infection events during early to mid-May-which generally correspond to preflowering and flowering time-on disease risk seems reasonable. However, it is important to note that the early season is not the only time that $P$. viticola infection takes place. Fruit tissues remain susceptible to Phomopsis fruit rot throughout the season $(8,28)$ and spores are available most of the growing season (5) to cause infection. 
Moreover, the mid-June variables for $\mathrm{T}$, $\mathrm{RH}, \mathrm{DM}$, and $\mathrm{C}$ had moderately high correlations with disease risk (D20 or D40), a further indication of the importance of this time period to disease development.

An application of fungicide during the dormant period was strongly associated with low risk of disease in commercial vineyards. Large negative correlation coefficients $(P<0.01)$ were observed between DOR and both D40 and D20; moreover, once DOR was included in a risk model for D20, no other variable could explain significantly more of the variation in disease and, hence, no other terms were included in those models (Table 6, models $\mathrm{K}$, L, and M). Based on the fungicide application records, growers applied either lime sulfur (calcium polysulfide) at the rate of 95 liters/ha in 948 liters of water or fixed copper (copper oxychloride) at a rate of $2.3 \mathrm{~kg} / \mathrm{ha}$ in 948 liters of water for the dormant application. These treatments were commonly applied to control grape powdery mildew (caused by Uncinula necator) or anthracnose (caused by Elsinoe ampelina) (7,26). Previously, we showed in field experiments (21) that a dormantperiod application of fungicide (lime sulfur applied at a rate of 95 liters/ha in 948 liters of water) provided consistent but only moderate control of Phomopsis cane and leaf spot (around 25 to 50 and 42 to $84 \%$ decrease in disease incidence and severity, respectively). The degree of control was significantly lower than found for treatment plots sprayed with a protectant fungicide throughout May and June (21).

Although variable DOR had a strong association with disease risk (especially for D20), it cannot be concluded from our results that a fungicide application during the dormant period is more important for control than fungicide applications during the early growing season. Growers who applied a dormant-period application (eight cases over 3 years) tended to have better fungicide coverage of the crop during the critical period of the early season (early to mid-May). For instance, average number of days with fungicide coverage from 1 to 20 May (i.e., $\mathrm{C}_{\mathrm{M} 1}$ and $\mathrm{C}_{\mathrm{M} 2}$ variables combined) was 11.2 days for vineyards which had received a dormant spray application and 3.2 days for vineyards which had not received a dormant spray. In other words, the $\mathrm{C}$ variables (for May) and DOR were correlated with each other. Thus, the effects of DOR and C for this survey are confounded in terms of risk of disease, and one cannot unambiguously separate out their individual effects. Given that only moderate control is obtained in field experiments (21) with a dormant spray, it is likely that the lower risk of disease in the survey is due to both dormant and early-growing-season fungicide applications. Considering the high costs of fungicide application, a fungicide treatment only during the dormant period would not be recommended (23); however, a spray during the dormant period is advantageous if powdery mildew or anthracnose is of concern, and may provide some level of control when weather conditions do not permit timely application of protectant fungicides during early to mid-May (23).

Disease incidence was relatively high over the 3 years of the survey throughout the state of Ohio, even though all growers were using protectant fungicide programs (at least during a portion of the growing season). Unlike Phomopsis disease on grape, other economically important grape diseases in Ohio, such as black rot (caused by Guignadia bidwellii), were not observed commonly in the commercial vineyards assessed in the 3-year survey, although no formal assessment of incidence of these diseases was made (M. Nita, unpublished). Thus, it appears that Phomopsis cane and leaf spot on grape is the most difficult disease to control using current management practices in Ohio. Yet, the observed relationship between good coverage of fungicide in critical early time periods and the reduced risk of the disease showed that improved disease control is possible in Ohio. Early-season application of fungicides and the improvement of fungicide timing with the use of the disease warning system (22) can increase efficiency of control of Phomopsis cane and leaf spot. Studies are needed on the effect of this disease on fruit yield and quality, as well as long-term effects of infected vines on disease and yield.

In conclusion, Phomopsis cane and leaf spot of grape was found in commercial vineyards throughout Ohio over 3 years. Although there was no significant effect of region on incidence, there was significant variability in leaf and internode disease incidence at all other tested spatial scales. Various statistical and modeling approaches (binary logistic regression and nonparametric correlations) showed that some of the among-farm or among-vineyard variation in disease risk could be attributed to differences in atmospheric moisture, predicted infection events (based on temperature and duration of high-moisture or precipitation events), and fungicide coverage in the early spring. Results were consistent with our current understanding of the disease, confirm the general impression (M. A. Ellis, unpublished) that the disease is not adequately controlled throughout the state of Ohio, and show that results from previous studies demonstrating the effects of certain management practices on disease control (21-23) have not yet been fully utilized by some growers. Similar combined survey and analytical approaches can be useful when there is interest in determining the variation in disease intensity in some designated area and accounting for some of this variability based on cropping practices and weather conditions.
ACKNOWLEDGMENTS

This work was supported by state and federal funds appropriated to the OARDC, The Ohio State University, and the Ohio Grape Industries Program.

\section{LITERATURE CITED}

1. Allison, P. D. 1999. Logistic Regression Using the SAS System: Theory and Application. SAS Institute, Cary, NC.

2. Carter, M. V. 1960. Further study on Eutypa armeniacea Hansf. \& Carter. Aust. J. Agric. Res. 11:498-504.

3. Chtioui, Y., Francl, L. J., and Panigrahi, S. 1999. Moisture prediction from simple micrometeorological data. Phytopathology 89:668672.

4. Crowe, M. J., and Coakley, S. M. 1978. Forecasting dew duration at Pendleton, Oregon, using simple weather observations. J. Appl. Meteorol. 17:1482-1487.

5. Cucuzza, J. D., and Sall, M. A. 1982. Phomopsis cane and leaf spot disease of grape vine: Effect of chemical treatments on inoculum level, disease severity, and yield. Plant Dis. 66:794-797.

6. De Wolf, E. D., Madden, L. V., and Lipps, P. E. 2002. Risk assessment models for wheat Fusarium head blight epidemics based on withinseason weather data. Phytopathology 93:428 435.

7. Ellis, M. A., Welty, C., Funt, R. C., Doohan, D., Wiliams, R. N., Brown, M., and Bordelon, B., eds. 2004. Midwest Small Fruit Pest Management Handbook. Ohio State University Extension, Columbus.

8. Erincik, O., Madden, L. V., Ferree, D. C., and Ellis, M. A. 2001. Effect of growth stage on susceptibility of grape berry and rachis tissues to infection by Phomopsis viticola. Plant Dis. 85 (5):517-520.

9. Erincik, O., Madden, L. V., Ferree, D. C., and Ellis, M. A. 2003. Temperature and wetnessduration requirements for grape leaf and cane infection by Phomopsis viticola. Plant Dis. 87 (7):832-840.

10. Everitt, B. S. 1999. The Cambridge Dictionary of Statistics. Cambridge University Press, Cambridge.

11. Francl, L., and Panigrahi, S. 1997. Artificial neural network models of wheat leaf wetness. Agric. For. Meteorol. 88:57-65.

12. Huber, L., and Gillespie, T. J. 1992. Modeling leaf wetness in relation to plant disease epidemiology. Annu. Rev. Phytopathol. 30:553-577.

13. Hughes, G., McRoberts, N., and Burnett, F. J. 1999. Decision-making and diagnosis in disease management. Plant Pathol. 48:174-153.

14. Kim, K. S., Taylor, S. E., Gleason, M. L., and Koehler, K. J. 2002. Model to enhance sitespecific estimation of leaf wetness duration. Plant Dis. 86:179-185.

15. Lal, B., and Arya, A. 1982. A soft rot of grapes caused by Phomopsis viticola. Indian Phytopathology 35(2):261-264.

16. Littell, R. C., Milliken, G. A., Stroup, W. W., Wolffinger, R. D., and Schabenberger, O 2006. SAS for Mixed Models, Second Edition. SAS Institute, Inc., Cary, NC.

17. Madden, L. V. 2006. Botanical epidemiology: some key advances and its continuing role in disease management. Eur. J. Plant Pathol. 115:2-23.

18. Malathrakis, N. E., and Baltzakis, N. G. 1976. Control of Dead-arm of Grapes. Poljopr. Znans. Smotra Agric. Conspectus Sci. 39 (49):261-269.

19. Mila, A. L., Carriquiry, A. L., and Yang, X. B 2004. Logistic regression modeling of prevalence of soybean Sclerotinia stem rot in the north-central region of the United States. Phytopathology 94:102-110.

20. Mostert, L., Crous, P. W., and Petrini, O. 2000. Endophytic fungi associated with shoots and 
leaves of Vitis vinifera, with specific reference to the Phomopsis viticola complex. Sydowia 52 (1):46-58.

21. Nita, M., Ellis, M. A., Wilson, L. L., and Madden, L. V. 2006. Application of fungicide during the dormant period and its effects on Phomopsis cane and leaf spot on grape disease intensity and inoculum production. Plant Dis. 90:1195-1200.

22. Nita, M., Ellis, M. A., Wilson, L. L., and Madden, L. V. 2006. Evaluation of a disease warning system for Phomopsis cane and leaf spot of grape: a field study. Plant Dis. 90:1239-1246

23. Nita, M., Ellis, M. A., Wilson, L. L., and Madden, L. V. 2007. Evaluations of new and current management strategies to control Phomopsis cane and leaf spot of grape. Online.
Plant Health Progress:doi:10.1094/PHP-20070726-1006-RS.

24. OARDC. 2005. OARDC weather system. Ohio Agricultural Research and Development Center (OARDC), Wooster.

25. Paul, P. A., and Munkvold, G. P. 2004. A model-based approach to preplanting risk assessment for gray leaf spot of maize. Phytopathology 94:1350-1357.

26. Pearson, R. C., and Goheen, A. C., eds. 1988. Compendium of Grape Diseases. American Phytopathological Society, St. Paul, MN.

27. Pscheidt, J. W., and Pearson, R. C. 1989. Effect of grapevine training systems and pruning practices on occurrence of Phomopsis cane and leaf spot. Plant Dis. 73 (10):825-828.

28. Pscheidt, J. W., and Pearson, R. C. 1989. Time of infection and control of Phomopsis fruit rot of grape. Plant Dis. 73:893-833.

29. Sutton, J. C., Gillespie, T. J., and Hildebrand, P. D. 1984. Monitoring weather factors in relation to plant disease. Plant Dis. 68:78-84.

30. Swets, J. A. 1988. Measuring the accuracy of diagnostic systems. Science 240:1285-1293.

31. Switras-Meyer, S., and Wilcox, W. F. 2003. Seasonal pattern of conidial release in Phomopsis viticola in New York. (Abstr.) Phytopathology 93:S82.

32. Wilks, D. S., and Shen, K. W. 1991. Threshold relative humidity duration forecasts for plan disease prediction. J. Appl. Meteorol. 30:463477.

33. Yang, X. B. 2003. Risk assessment: concepts, development, and future opportunities. Plant Health Progress:doi:10.1094/PHP-2003-111302-RV. 